\title{
Environmental determinants of the distribution of Chagas disease vectors in south-eastern Guatemala
}

\author{
Dulce Maria Bustamante, 1,2 Maria Carlota Monroy$^{1}$, Antonieta Guadalupe Rodas ${ }^{1}$, \\ Jaime Abraham Juarez ${ }^{3,4}$, John B. Malone ${ }^{5}$ \\ ${ }^{1}$ Laboratory of Applied Entomology and Parasitology, Department of Biology, School of Chemical Sciences \\ and Pharmacy, San Carlos University, Guatemala; ${ }^{2}$ Current address: Florida Medical Entomology \\ Laboratory, University of Florida, Vero Beach, FL, USA; ${ }^{3}$ Entomology Section, Ministry of Public Health \\ and Social Assistance, Guatemala; ${ }^{4}$ Current address: Pan American Health Organization, PO Box 383, \\ Guatemala City, Guatemala; ${ }^{5}$ Department of Pathobiological Sciences, School of Veterinary Medicine, \\ Louisiana State University, Baton Rouge, LA, USA
}

\begin{abstract}
The associations between the presence of triatomines and environmental variables were studied using correlation analysis and logistic regression models for a sample of villages in the south-eastern provinces of Guatemala. Information on the presence of Triatoma dimidiata, T. nitida and Rhodnius prolixus came from entomological surveys carried out by the Ministry of Health of Guatemala as part of its vector control programme. Environmental information for each village was extracted from digital thematic maps developed by the Ministry of Agriculture. The presence of $T$. nitida was found to be significantly associated with the average minimum temperature. The odds of presence of T. nitida in a village decreased as the average minimum temperature increased. T. nitida exists at altitudes above 1000 $\mathrm{m}$ above sea level in temperate regions. The presence of $R$. prolixus showed a significant positive association with maximum absolute temperature and relative humidity. The logistic regression model for $R$. prolixus showed a good fit and predicted suitable habitats in the provinces of Chiquimula, Zacapa and Jalapa, which agrees with the known distribution of the species. Habitat partitioning between R. prolixus and T. dimidiata is suggested by their significant and opposite associations with maximum absolute temperature. Improved models to predict suitable habitats for $T$. dimidiata hold promise for spatial targeting of integrated vector management.
\end{abstract}

Keywords: Triatominae, Chagas disease, Guatemala, environment, geographic information system.

\section{Introduction}

Guatemala has three triatomine bug species that can colonize human dwellings and are natural vectors of Trypanosoma cruzi, the causal agent of Chagas disease. These are Triatoma dimidiata, Rhodnius prolixus, and T. nitida (Tabaru et al., 1999). The former two species are considered the principal Chagas disease vectors in the country

Corresponding author:

Dulce Maria Bustamante

Florida Medical Entomology Laboratory

200 9th Street SE, Vero Beach, FL 32692, USA

Tel. +1 772778 7200; Fax +1 7727787205

E-mail: dbusta1@ufl.edu based on their distribution and vector capacity (Schofield and Dujardin, 1997; Monroy et al., 2003c). T. nitida appears to have less vector importance due to its scarce presence in domestic habitats and inefficient defecation patterns (Monroy et al., 2003b). However, an increasing number of T. nitida colonizations in domestic and peridomestic habitats in north-central Guatemala have been documented recently (Monroy et al., 2003b).

Nation-wide surveys have shown that $T$. dimidia$t a$ is distributed in 21 of the 22 provinces in Guatemala (Monroy et al., 2003c). R. prolixus was initially detected in 9 provinces by the Ministry of Health $(\mathrm{MoH})$ of Guatemala, but the species is abundant only in the provinces of Zacapa and 
Chiquimula (Monroy et al., 2003c). T. nitida has been found in 9 provinces in Guatemala (Monroy et al., 2003b). The preferred microhabitats for T. dimidiata are unplastered adobe walls with cracks, and this vector species is often found under bed mattresses (Monroy et al., 1996, 1998). In the peridomiciliary environment, $T$. dimidiata exists in chicken coops and other types of animal corrals constructed with materials suitable for providing shelter for the insect, especially adobes. $R$. prolixus can be found in house roofs that are made from vegetation materials (e.g. thatched grass roofs) (Monroy et al., 1998) and only occasionally under bed mattresses.

T. nitida has been found in adobe walls in houses and chicken coops (Monroy et al., 2003b).

Habitat preferences influenced by climate factors determine the distribution of triatomines. These insects appear to be able to move between microclimates within their habitats while seeking the most favorable conditions. Within the fronds of palm trees, triatomines can be found on the inner leaves where temperatures are kept relatively constant at $22-23^{\circ} \mathrm{C}$, while the temperatures in the external leaves vary from 16 to $32^{\circ} \mathrm{C}$ (Pifano, 1969; Monroy et al., 2003a). In rural houses in Argentina, T. infestans is commonly present in microenvironments that maintain low relative humidity and a delayed increase in relative humidity compared to the outside conditions. This is consistent with the preference of T. infestans for dry conditions, e.g. habitats where the relative humidity is only $20 \%$ (Lazzari et al., 1998; Lorenzo and Lazzari, 1999).

Variability in climate variables can help explain distribution of triatomines at continental scales. The alti-latitudinal distribution of many triatomines has been well studied (for a review see Carcavallo, 1999). For example, air temperature variability monitored by remote sensors over a period of 18 years, correctly explained the presence of $T$. infestans in $70 \%$ of the known positive localities in the South American subcontinent (Gorla, 2002).

The environmental conditions where triatomines exist at local scales (e.g. province) is of special interest for vector control. These environmental conditions could be described as a function of altitude, climate, vegetation types and land uses. Differences in altitude and mean annual precipitation were important in the habitat partitioning of 8 Triatoma species and R. prolixus in the state of Oaxaca, Mexico (Ramsey et al., 2000). The distribution of domestic T. dimidiata in Yucatan, Mexico, was found to be associated with environmental factors such as wind speed, precipitation rate, vegetation type, relative humidity and maximum temperature (Dumontiel and Gourbiere, 2004).

Here we present a first assessment aimed to improve our understanding of how the outdoor environmental conditions determine local scale distributions of triatomines in Guatemala. This type of information can be helpful in evaluating isolation of populations or in the long-term monitoring of areas that could be more problematic to control. Specific climate conditions might interact with housing conditions and quality of spraying, to influence the persistence of triatominae populations. In this study we examine the associations between a group of climate variables and triatomine presence at five provinces from south-eastern Guatemala, which is the endemic region for Chagas disease in the country and the first region to undergo an extensive control programme directed towards triatomines.

\section{Materials and methods}

\section{Data}

The entomological data came mainly from the baseline entomological surveys carried out by the Guatemalan $\mathrm{MoH}$ during the initial phase of the vector control campaign. A list of 1341 villages from the provinces of Chiquimula, Jalapa, Jutiapa, Santa Rosa and Zacapa (Fig. 1), was obtained from the MoH. All these villages had been assessed for the presence or absence of T. dimidiata, T. nitida and R. prolixus, between the years 1999 and 2002. The searches were done by the man-hour collection method, selecting for houses that favor the presence of triatomines (for more details see Nakagawa et al., 2003a,b). The lati- 


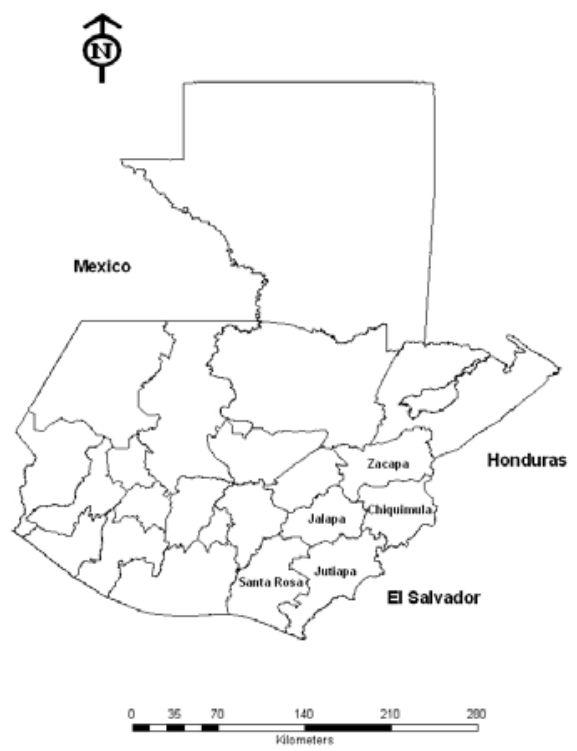

Fig. 1. Map of Guatemala showing the five south-eastern provinces included in the present study.

tude and longitude of these villages were determined using the GEOnet Names Server (GNS), a database of foreign geographic names from the National Agency of Geospatial Intelligence of the U.S. Board on Geographic names (http://gnswww.nga.mil/geonames/GNS). From the 1341 villages only 731 (54.5\%) were listed in the GNS and they were the ones used for the present study (Table 1). Point shape-files were created with the village information using the package ArcGIS, version 8.3 (ESRI Inc., Redlands, CA, USA), with data on each village linked to a point centered on the latitude-longitude coordinates.
The Geographical Information Systems Laboratory from the Ministry of Agriculture of Guatemala (SIG-MAGA, i.e. its initials in Spanish) provided us with digital thematic maps of climate variables in shapefile or ArcInfo coverage formats. These maps were in a 1:250,000 scale and included the following 10 parameters:

(i) potential evapotranspiration (PET);

(ii) relative humidity $(\mathrm{RH})$;

(iii) annual mean temperature (ANTMEAN);

(iv) minimum absolute temperature (TMIN),

(v) minimum mean temperature (AVTMIN);

(vi) maximum absolute temperature (TMAX);

(vii) maximum mean temperature (AVTMAX);

(viii) annual mean precipitation (PRE);

(ix) minimum precipitation (PREMIN); and

(x) maximum precipitation (PREMAX).

Temperatures were expressed in centigrades $\left({ }^{\circ} \mathrm{C}\right)$, precipitation variables and potential evapotranspiration in millimeters $(\mathrm{mm})$ and relative humidity as a percentage $(\%)$. All these digital thematic maps were created by the SIG-MAGA based on information generated between the years 1961 and 1997 by climate stations of the National Institute of Seismology, Vulcanology, Meteorology and Hydrology of Guatemala, located throughout the country.

The thematic maps of climate variables originally showed isolines of temperature, precipitation, humidity or evapotranspiration. Extrapolation of the values between two isolines was done using the 3D Analyst extension within ArcGIS, version 8.3. The line shape-files were converted to a TIN format

Table 1. Number of villages per province where each triatomine species was found, and the total number of villages that were found infested or uninfested with triatomines.

\begin{tabular}{|c|c|c|c|c|c|c|}
\hline \multirow{2}{*}{$\begin{array}{l}\text { Triatomine } \\
\text { species and status }\end{array}$} & \multicolumn{5}{|c|}{ Province } & \multirow[b]{2}{*}{ Total } \\
\hline & Chiquimula & Jalapa & Jutiapa & Santa Rosa & Zacapa & \\
\hline T. dimidiata & 81 & 64 & 168 & 49 & 26 & 388 \\
\hline R. prolixus & 172 & 26 & 6 & 1 & 23 & 228 \\
\hline T. nitida & 4 & 9 & 1 & 0 & 0 & 14 \\
\hline Infested & 183 & 82 & 168 & 49 & 41 & 523 \\
\hline Uninfested & 37 & 4 & 116 & 14 & 37 & 208 \\
\hline Total & 220 & 86 & 284 & 63 & 78 & 731 \\
\hline
\end{tabular}


(Convert Feature to TIN), specifying 0.008 cell size (representing spacing of approximately $1 \mathrm{~km}$ ). The TIN shape-files were then converted to GRID shape-files (Convert TIN to GRID), where each cell had a value for the climate variable.

SIG-MAGA also provided us with polygon shapefiles with maps of the political divisions of Guatemala, provinces and municipalities. All the thematic shape-file maps had a projection UTM Zone 15 DATU NAD 27 and were re-projected to latitudelongitude decimal-degrees, WGS 1984 format, using the ArcToolbox package within ArcGIS, version 8.3.

Altitude (ALT) information was obtained from the U.S. Geological Survey free data base GTOPO30, which is a global digital elevation model with an horizontal grid spacing of 30 arc seconds (approximately $1 \mathrm{~km}$ ) (http://edc.usgs.gov/products/elevation/ gtopo30/gtopo30.html). Altitudes were in meters above sea level ( $\mathrm{m}$ asl).

The digital maps were all imported into ArcView version 3.2 and information by village was obtained using the following procedure. An Avenue Script from ESRI was loaded into ArcView. This script allows creation of buffers around selected points in active themes (in our case, the villages). Circular buffer zones of $1 \mathrm{~km}$ radius were created around each village and stored in a new shape-file. The buffers were used to extract information from grid cells contained within each buffer zone for climate variables and altitude, using the function "Summarize Zones". This provided an average for each data layer of the area within the buffer. Average values were then assigned to each village point record in a Dbase attribute table, creating a spreadsheet containing the data on the triatomines, climate and other information for each village.

\section{Univariate analysis}

The correlation between the presence of each of the triatomine species with the climate variables and altitude was studied using a Pearson correlation coefficient. When one variable is dichotomous (i.e. 0 or 1) and the other variable is continuous, a Pearson correlation is equivalent to a point biserial correlation (SAS Institute, 2002).

\section{Multivariate analysis}

A simple random sample of 585 villages was taken from the 731 total villages $(80.0 \%)$. This sample was used to build a logistic regression model of the probability of presence of each triatomine species, using a stepwise procedure to select for variables significantly associated with the response variable and to reduce potential co-linearity problems. Goodness-offit of the models was assessed with the score statistic (Stokes et al., 2000). Maps of predicted probabilities of presence were created using the regression model equations and the map calculator of the "Spatial Analyst" extension of ArcGIS, version 8.3.

The sensitivity and specificity of the models in the prediction of the presence of triatomines based on climate variables and altitude was evaluated using the method of King et al. (2004). This method was used to select the threshold of presence, which is the probability value below which the species is considered absent and above which the species can be considered present. Briefly, the threshold will be the probability value for which the higher value of the Kappa statistic is obtained (King et al., 2004). Nine different threshold values were tested (i.e. 0.1, 0.2, $0.3,0.4,0.5,0.6,0.7,0.8$ and 0.9$)$. After a threshold was selected, the percentage of true positives (sensitivity) and true negatives (specificity) predicted by the model was calculated.

The regression models were used to predict the probability of presence of each triatomine species in the sub-sample of 146 villages that were not included in the building of the model. The correlation between the observed and the predicted values for those villages was calculated. Finally, the information from the control villages was used to build a second logistic regression model for each species, in order to validate if these second models preserved the same variables as the original ones.

Univariate and multivariate analyses were con- 
ducted as described by Elainem et al. (2003) and Dumontiel and Gourbiere (2004). The statistical analyses were done in SAS, version 9.1 (SAS Institute, 2002).

\section{Results}

The climate conditions in the triatomine-infested villages, stratified by province, are summarized in Table 2. Only one village was reported infested with $R$. prolixus in Santa Rosa and a single T. nitida female was collected in one house in Jutiapa.

\section{Univariate analysis}

The correlations between the presence of triatomines and the environmental variables were generally low (Table 3). A few variables were above a correlation magnitude of 0.2 . Those were the variables considered most relevant here and they were TMAX and TMIN for $T$. dimidiata; RH, PREMAX and TMAX for R. prolixus, and AVTMIN for T. nitida.

Both $T$. dimidiata and $R$. prolixus had a relatively high and significant correlation with the variable TMAX, but the correlations were of opposite signs indicating an opposite pattern. Localities where

Table 2. Summary of climate conditions in the triatomine-infested villages, stratified by province and by species. The values are the mean and standard errors for each of the climate variables.

\begin{tabular}{|c|c|c|c|c|c|c|}
\hline \multirow{2}{*}{ Variables } & \multirow{2}{*}{$\begin{array}{l}\text { Triatomine } \\
\text { species }\end{array}$} & \multicolumn{5}{|c|}{ Province } \\
\hline & & Chiquimula & Jalapa & Jutiapa & Santa Rosa & Zacapa \\
\hline \multirow{3}{*}{ Altitude (masl) } & T. dimidata & $938.0 \pm 2.5$ & $1115.6 \pm 3.8$ & $904.1 \pm 1.5$ & $956.2 \pm 7.4$ & $676.6 \pm 9.8$ \\
\hline & R. prolixus & $927.1 \pm 1.4$ & $1122.8 \pm 9.1$ & $1229.7 \pm 37.8$ & 960.0 & $740.3 \pm 12.9$ \\
\hline & T. nitida & $1210.0 \pm 38.8$ & $1367.0 \pm 26.2$ & 889.3 & & \\
\hline \multirow{3}{*}{$\begin{array}{l}\text { Annual Mean } \\
\text { Temperature }\left({ }^{\circ} \mathrm{C}\right)\end{array}$} & T. dimidata & $20.53 \pm 0.03$ & $19.87 \pm 0.04$ & $21.67 \pm 0.01$ & $20.81 \pm 0.05$ & $24.44 \pm 0.10$ \\
\hline & R. prolixus & $20.80 \pm 0.01$ & $19.90 \pm 0.08$ & $20.16 \pm 0.21$ & 19.98 & $22.51 \pm 0.12$ \\
\hline & T. nitida & $18.62 \pm 0.24$ & $18.16 \pm 0.08$ & 22.00 & & \\
\hline \multirow{3}{*}{$\begin{array}{l}\text { Annual Mean } \\
\text { Precipitation (mm) }\end{array}$} & T. dimidata & $1057.7 \pm 3.4$ & $1003.4 \pm 3.1$ & $1209.3 \pm 1.3$ & $1873.8 \pm 5.7$ & $794.7 \pm 10.3$ \\
\hline & R. prolixus & $1084.7 \pm 1.8$ & $982.7 \pm 8.4$ & $1258.0 \pm 36.5$ & 1992.1 & $971.2 \pm 15.8$ \\
\hline & T. nitida & $1024.3 \pm 44.6$ & $1203.0 \pm 34.6$ & 1394.7 & & \\
\hline
\end{tabular}

Table 3. Correlation $(\mathrm{r})$ between presence of triatomines and climate variables and altitude, and its significance.

\begin{tabular}{|c|c|c|c|c|c|c|}
\hline \multirow{3}{*}{ Variables } & \multicolumn{6}{|c|}{ Triatomine species } \\
\hline & \multicolumn{2}{|c|}{ T. dimidiata } & \multicolumn{2}{|c|}{ R. prolixus } & \multicolumn{2}{|c|}{ T. nitida } \\
\hline & $\mathrm{r}$ & $\mathrm{p}$ & $\mathrm{r}$ & $\mathrm{p}$ & $\mathrm{r}$ & $\mathrm{p}$ \\
\hline ALT & 0.11 & $<0.01$ & 0.07 & 0.04 & 0.18 & $<0.0001$ \\
\hline PET & -0.12 & $<0.001$ & -0.09 & 0.01 & -0.12 & $<0.01$ \\
\hline $\mathrm{RH}$ & 0.03 & 0.47 & 0.40 & $<0.0001$ & 0.08 & 0.04 \\
\hline PRE & 0.13 & $<0.001$ & -0.16 & $<0.0001$ & 0.004 & 0.92 \\
\hline PREMAX & 0.16 & $<0.0001$ & -0.26 & $<0.0001$ & 0.01 & 0.80 \\
\hline PREMIN & 0.17 & $<0.0001$ & -0.18 & $<0.0001$ & -0.002 & 0.95 \\
\hline ANTMEAN & -0.12 & $<0.001$ & -0.18 & $<0.0001$ & -0.17 & $<0.0001$ \\
\hline AVTMAX & -0.12 & $<0.01$ & -0.04 & 0.32 & -0.18 & $<0.0001$ \\
\hline TMAX & -0.24 & $<0.0001$ & 0.31 & $<0.0001$ & -0.10 & 0.01 \\
\hline AVTMIN & -0.10 & $<0.01$ & -0.07 & 0.07 & -0.23 & $<0.0001$ \\
\hline TMIN & -0.20 & $<0.0001$ & 0.15 & $<0.0001$ & -0.14 & $<0.0001$ \\
\hline
\end{tabular}


T. dimidiata was present had an average TMAX of $38.2 \pm 3.9^{\circ} \mathrm{C}$ and where T. dimidiata was not collected, the average TMAX was $40.1 \pm 3.7^{\circ} \mathrm{C}$. For $R$. prolixus those values were $40.9 \pm 3.5^{\circ} \mathrm{C}$ and $38.2 \pm 3.8^{\circ} \mathrm{C}$, respectively.

\section{Multivariate analysis}

The variables that did not have a significant association with the presence of triatomines were excluded from the logistic regression model by a stepwise backward procedure (Table 4). There was lack of fit $(\mathrm{p}<0.05$, goodness-of-fit statistic) for the models for $R$. prolixus and T. dimidiata, suggesting that other variables that were not available to construct these models, or interactions that were left out, were important to explain the variation of the probability of presence for those two species.

The best reclassifications (higher Kappa values) were obtained with thresholds of 0.4 for $R$. prolixus and $T$. dimidiata, and a threshold of 0.2 for T. nitida (Table 4). Considering these thresholds, the model for $R$. prolixus has a high sensitivity and specificity. The $T$. dimidiata model fails to detect true negatives and the T. nitida model fails to detect true positives and therefore low Kappa values were obtained for these models. The Kappa values suggest a substantially good reclassification for the $R$. prolixus model,

Table 4. Logistic regression models by species and their respective goodness-of-fit statistics, and evaluation statistics of the logistic regression model. Threshold values where obtained with a method presented by King et al. (2004).

\begin{tabular}{|c|c|c|c|c|c|c|c|c|}
\hline \multirow{2}{*}{$\begin{array}{l}\text { Triatomine } \\
\text { species }\end{array}$} & \multirow{2}{*}{$\begin{array}{l}\text { Model } \\
\text { Estimated Logit }(\mathrm{p}=1)=\mathrm{z}\end{array}$} & \multicolumn{3}{|c|}{ Goodness-of-fit statistic } & \multicolumn{4}{|c|}{ Classification evaluation } \\
\hline & & $\begin{array}{c}\text { Chi } \\
\text { square }\end{array}$ & df & $\mathrm{p}$ & Kappa & $\begin{array}{c}\text { Threshold } \\
\text { value }\end{array}$ & Sensitivity & Specificity \\
\hline R. prolixus & $\begin{array}{c}\mathrm{z}=-25.98-0.19 * \text { ANTMEAN }+ \\
0.33 * \text { TMAX }+0.002 * \text { PRE }- \\
0.002 * \text { PREMAX }+0.23 * \text { RH }\end{array}$ & 12.9 & 6 & 0.04 & 0.64 & 0.4 & $80 \%$ & $85 \%$ \\
\hline T. dimidiata & $\mathrm{z}=4.37-0.10 *$ TMAX $-0.08 *$ TMIN & 22.3 & 9 & 0.01 & 0.19 & 0.4 & $84 \%$ & $35 \%$ \\
\hline T. nitida & $\mathrm{z}=-3.05+0.003 *$ ALT $-0.29 *$ AVTMIN & 11.1 & 9 & 0.27 & 0.21 & 0.2 & $20 \%$ & $99 \%$ \\
\hline
\end{tabular}

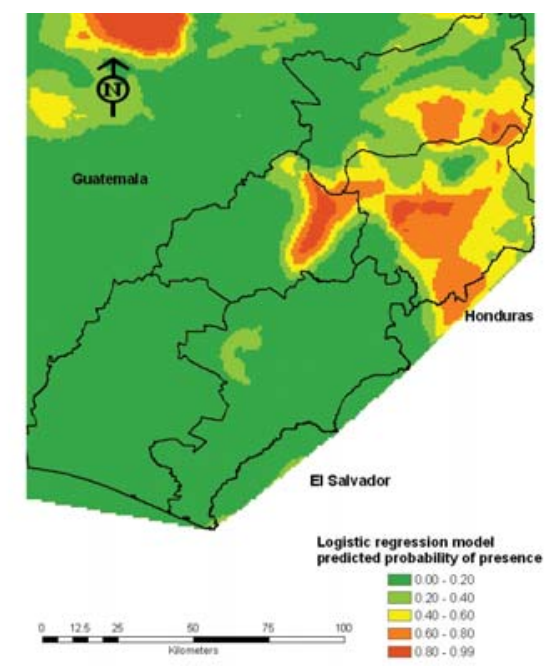

Fig. 2. Probabilities of presence of T. dimidiata in five provinces of south-eastern Guatemala. The probabilities were calculated using the logistic regression model for T. dimidiata (see Table 4).

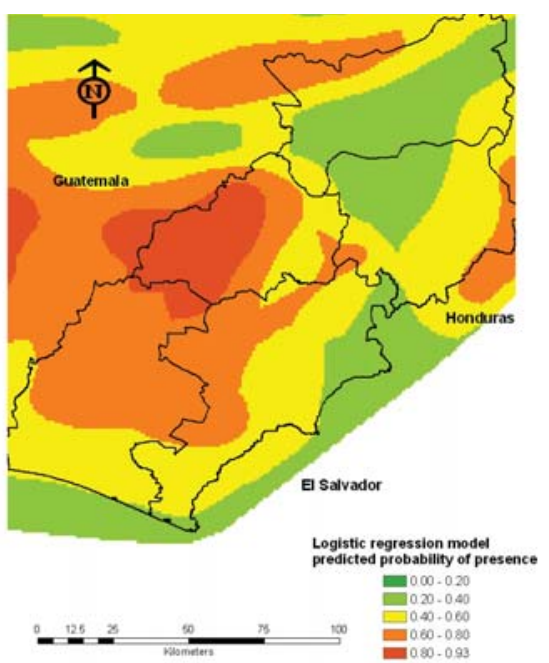

Fig. 3. Probabilities of presence of $R$. prolixus in five provinces of south-eastern Guatemala. The probabilities were calculated using the logistic regression model for $R$. prolixus (see Table 4). 


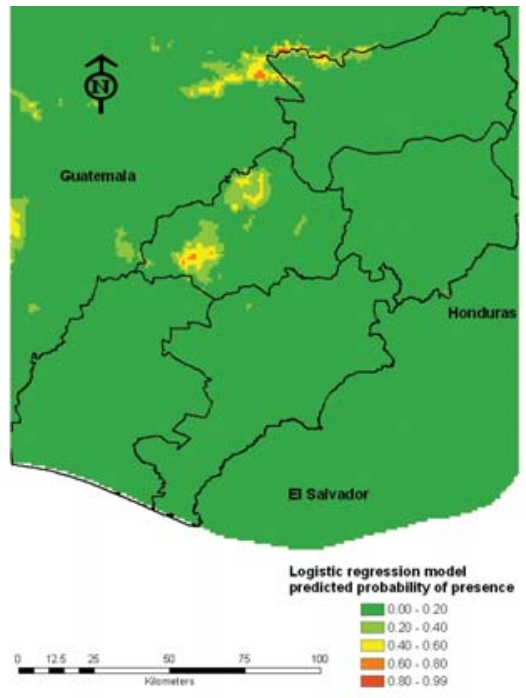

Fig. 4. Probabilities of presence of T. nitida in five provinces of south-eastern Guatemala. The probabilities were calculated using the logistic regression model for T. nitida (see Table 4).

and random reclassifications for the $T$. dimidiata and T. nitida models (Landis and Koch, 1977).

Taking these thresholds into account, the maps of predicted probabilities of presence for the region (Figs. 2-4) suggest focalized distributions for $R$. prolixus and T. nitida, and widespread presence for $T$. dimidiata.

The logistic regression models were used to calculate the predicted probabilities of presence of the triatomines in the sub-sample of 146 villages not included in building the model. The correla- tions between the observed presence/absence of triatomines in the control villages and the values predicted by the model were $\mathrm{r}=0.64(\mathrm{p}<0.0001)$ for $R$. prolixus, $\mathrm{r}=0.31$ ( $\mathrm{p}<0.0001)$ for $T$. nitida, and $\mathrm{r}=0.17(\mathrm{p}=0.04)$ for $T$. dimidiata. These results suggest a good predictive value of the $R$. prolixus model. The correlation was relatively high for the T. nitida model and rather poor for the $T$. dimidiata model.

From these models it is possible to study the type of associations between variables using odds ratios (OR) (Table 5). The R. prolixus PRE and PREMAX data showed ORs close to 1 , therefore the presence of $R$. prolixus did not appear to be strongly associated with these variables. For the other three variables in the model, the odds of presence of $R$. prolixus increase by $39 \%$ as the TMAX increases by $1^{\circ} \mathrm{C}$ and by $25 \%$ when the $\mathrm{RH}$ increases by $1 \%$, holding all other conditions constant. The odds of presence of $R$. prolixus decrease by $17 \%$ when ANTMEAN increases by $1^{\circ} \mathrm{C}$. Similarly, the odds of presence of $\mathrm{T}$. dimidiata decrease by $10 \%$ when TMAX increases by $1{ }^{\circ} \mathrm{C}$ and by $8 \%$ when TMIN increases by $1^{\circ} \mathrm{C}$. The odds of presence of $T$. nitida decrease by $25 \%$ when AVTMIN increases by $1{ }^{\circ} \mathrm{C}$ and they increase minimally $(3 \%)$ when altitude increases by $100 \mathrm{~m}$.

Finally, the subsample of 146 villages was used in a second logistic regression with the same specifications as those of the first models. The new models

Table 5. Odds ratio estimates derived from the logistic regression models.

\begin{tabular}{|c|c|c|c|c|}
\hline \multirow[t]{2}{*}{ Triatomine species } & \multirow[t]{2}{*}{ Effect } & \multirow[t]{2}{*}{ Point estimate } & \multicolumn{2}{|c|}{$95 \%$ Wald confidence limits } \\
\hline & & & Lower & Upper \\
\hline \multirow[t]{5}{*}{ R. prolixus } & ANTMEAN & 0.83 & 0.75 & 0.92 \\
\hline & TMAX & 1.39 & 1.27 & 1.53 \\
\hline & PRE & 1.002 & 1.001 & 1.004 \\
\hline & PREMAX & 0.998 & 0.997 & 0.999 \\
\hline & $\mathrm{RH}$ & 1.25 & 1.19 & 1.32 \\
\hline \multirow[t]{2}{*}{ T. dimidiata } & TMAX & 0.90 & 0.85 & 0.96 \\
\hline & TMIN & 0.92 & 0.87 & 0.98 \\
\hline \multirow[t]{2}{*}{ T. nitida } & ALT & 1.003 & 1.001 & 1.006 \\
\hline & AVTMIN & 0.75 & 0.60 & 0.93 \\
\hline
\end{tabular}


Table 6. Logistic regression models for the evaluation sub-sample, by species and their respective goodness-of-fit statistics, obtained with a stepwise backward elimination procedure.

\begin{tabular}{lcccc}
\hline Triatomine species & Model & \multicolumn{3}{c}{ Goodness-of-fit statistic } \\
\cline { 3 - 4 } & Estimated Logit $(\mathrm{p}=1)=\mathrm{z}$ & Chi square & $\mathrm{df}$ & $\mathrm{p}$ \\
\hline R. prolixus & $\mathrm{z}=-35.86+0.35 *$ TMAX $+0.28 * \mathrm{RH}$ & 17.3 & 9 & 0.04 \\
T. dimidiata & $\mathrm{z}=4.92-0.11 *$ TMAX & 21.0 & 10 & 0.02 \\
T. nitida & $\mathrm{z}=4.24-0.50 *$ AVTMIN & 10.3 & 10 & 0.42 \\
\hline
\end{tabular}

produced (Table 6) retained the variables TMAX and RH for $R$. prolixus, TMAX for $T$. dimidiata and AVTMIN for T. nitida. The signs and magnitudes of the parameter estimates were similar to the ones in the first models, supporting the importance of those variables in explaining the variation of the presence of the triatomines.

\section{Discussion}

In the present study, climate variables showed significant associations with the presence of triatomines in five provinces from south-eastern Guatemala. These variables were the minimum average temperature for $T$. nitida, the maximum absolute temperature and relative humidity for $R$. prolixus, and the maximum absolute temperature for T. dimidiata.

From our results, suitable habitats can be clearly defined for T. nitida in this region of Guatemala. This species was found in localities at relatively higher altitudes (usually above $1000 \mathrm{~m}$ ) and lower annual mean temperatures (between 17 and $20^{\circ} \mathrm{C}$ ), than the other two triatomine species in the provinces of Jalapa and Chiquimula (Table 2). Previous descriptive studies of $T$. nitida reported that the species is present in temperate climates and altitudes ranging from 960 to $1500 \mathrm{~m}$ (Monroy et al., 2003b). Consistent with these observations, the logistic regression model showed that as the minimum mean temperature increases, the probability of presence of $T$. nitida decreases. T. nitida is not considered a primary vector due to its low densities and inefficient defecation patterns, but it has the potential to colonize human dwellings and it also has relatively high infection rates with $T$. cruzi (Monroy et al., 2003b,c), thus its presence should be monitored in villages within the areas with the climatic conditions here described. In the highlands of the north-central province of Huehuetenango, T. nitida domestic colonizations have increased after extensive residual sprayings (personal communications with personnel at the $\mathrm{MoH}$, Guatemala) and it would be of interest to examine if this species could occupy the empty niches left by T. dimidiata or R. prolixus.

The regression model for $R$. prolixus showed good agreement between observed and predicted occurrence of this species, and the model also produced predictions that correlated well with the observed values from the sub-sample. This was a good model that detected significant factors for the distribution of $R$. prolixus in the studied region, but is not recommended for predictions outside this geographic area. It has been observed that environmental risk models cannot be reliably extrapolated outside the ecological zone where they were developed (Malone, 2005).

Maximum absolute temperature and relative humidity showed significant associations with $R$. prolixus presence. The effects of temperature and humidity in the life cycle of $R$. prolixus have been previously described. $R$. prolixus completes its life cycle faster ( 86.7 days) at $28^{\circ} \mathrm{C}$ and $75 \% \mathrm{RH}$ (Luz et al., 1999). Egg eclosion or molting does not occur 
at $15^{\circ} \mathrm{C}$ and $86-97 \% \mathrm{RH}$, and only a few insects molt at $35^{\circ} \mathrm{C}$ and $75 \%$ RH. Humidity has been recognized as a critical factor in the development of $R$. prolixus, particularly with regard to the eclosion of eggs (WHO, 2000).

Interestingly, the maximum absolute temperature was the most relevant variable associated with the presence not only of $R$. prolixus, but also of T. dimidiata. The maximum absolute temperature represents the highest temperature registered in a 1 -year period. We do not believe that the maximum absolute temperature is the restricting factor for triatomine distributions in southeastern Guatemala, but this variable may be a descriptor for temperature patterns in the region. The number of days at certain temperatures should be critical for the distribution of these insects. Curto de Casas and Carcavallo (1984) explained that for triatomines in the Patagonia region of Argentina, it was not the lowest temperature that was critical for their distribution but the number of days with temperatures above $20^{\circ} \mathrm{C}$.

Even though the maximum absolute temperature might not be the critical factor in the distribution of $R$. prolixus and $T$. dimidiata, this variable reflected a pattern of habitat partitioning between the two species. From the signs of the correlation coefficients and the behaviour of the OR estimates, it is possible to infer that the odds of finding $R$. prolixus in a village increases with the maximum absolute temperature, while the odds of finding $T$. dimidiata decreases in this situation. In previous studies in Guatemala, it was observed that in areas where $R$. prolixus is abundant, $T$. dimidiata is not (Monroy et al., 2003c). From 867 triatomines collected in Chiquimula, $90 \%$ were R. prolixus and $10 \%$ were T. dimidiata. In Zacapa, from 1536 triatomines collected, the respective ratio was $99 \%$ to $1 \%$ (Monroy et al., 2003c). From the data used in the present study, average maximum absolute temperatures for the provinces of Chiquimula and Zacapa were $41.4^{\circ} \mathrm{C}$ and $43.7^{\circ} \mathrm{C}$, respectively. The respective average maximum absolute temperatures for Jutiapa and Santa
Rosa were $38.2^{\circ} \mathrm{C}$ and $33.9^{\circ} \mathrm{C}$, and only T. dimidiata were collected in those provinces. In Jalapa, where the average maximum absolute temperature is $35.4^{\circ} \mathrm{C}$ (but altitudes are generally higher), only 97 triatomines were found and T. dimidiata and $R$. prolixus represented $26 \%$ and $22 \%$, respectively, of the triatomines collected and the rest were T. nitida (Monroy et al., 2003a). In this connection, it is necessary to remember that these numbers do not come from a random sample, but from convenience samples where houses were selected for their suitability to hold triatomine populations.

Nevertheless, it appears as if $R$. prolixus thrives in generally warmer habitats where $T$. dimidiata is not nearly as abundant. These associations could be studied in other countries (Honduras) to elucidate if this pattern recurs. Other factors could be involved in the establishment of such patterns and should also be considered. The types of roofing materials are of high importance in assessing the distribution of $R$. prolixus. In El Salvador this species has become very rare, possibly because of the drastic reduction in the use of thatch for roofing (Cedillos et al., 2001). In the early 1940 s $R$. prolixus was present in the lowlands of the pacific coast of Guatemala (Blanco, 1943) but in more recent surveys (Tabaru et al., 1999; Monroy et al., 2003c) the species was not detected in those areas and it was abundant only in Zacapa and Chiquimula. T. dimidiata is at present the only vector that can be found in the pacific lowlands. Changes in housing conditions (replacing thatch roofs with metal sheets) could be responsible for the disappearance of $R$. prolixus in that particular region.

The results from the present study support a restricted distribution of $R$. prolixus and add more evidence for the viability of the targeted control of the species in the region (Schofield, 2000). In the province of Zacapa, a high reduction of infestation by $R$. prolixus has been achieved with chemical control methods that have reduced infestation levels from $8.8 \%$ to $0 \%$ (Nakagawa et al., 2003a). There has also been success in the chemi- 
cal control of $T$. dimidiata. Infestations have been reduced from $5.3 \%$ to $0.5 \%$ and from $36 \%$ to $8.9 \%$ in Zacapa and Jutiapa, respectively (Nakagawa et al., 2003a,b). However, T. dimidiata has proven more challenging to control because it can re-infest previously sprayed villages (Nakagawa et al., 2003b). Between two and three rounds of residual sprayings are necessary to control $T$. dimidiata in a village, but the long-term effect of this approach is yet to be evaluated (Hashimoto et al., 2006).

T. dimidata was predicted to be widely present in south-eastern Guatemala, with high predicted probabilities of presence in most of the region except for large portions in the provinces of Zacapa and Chiquimula (Fig. 2). However, it would be useful to develop a more sensitive model that further stratifies the distribution of $T$. dimidiata to support control and surveillance activities. Models that take into consideration abundance (Dumontiel and Gourbiere, 2004), the limits of temperature for development and the growing degree days necessary to complete the life cycle (McNally, 2003; Malone, 2005) should be considered to more accurately explain $T$. dimidiata spatial patterns in Guatemala or elsewhere based on climate regime. If applied on a large-scale these models would need to take into consideration the intraspecific variability of $T$. dimidiata and the high divergence that has been observed among some populations; several research groups have suggested that $T$. dimidiata is a complex of species (Marcilla et al., 2001; Bustamante et al., 2004; Panzera et al., 2006). Laboratory studies of the life cycles under different conditions of temperature and relative humidity of the different populations (subspecies or maybe species) that make up $T$. dimidiata, should be prioritized to generate the information needed to develop predictive models.

For the present study, entomological information was not gathered in a randomized fashion and it cannot be ruled out that some villages were erroneously reported as non-infested. There were difficulties in geo-referencing the villages and almost half of the original dataset was not included in the analysis $(46 \%)$. The scale of the digital maps was coarse for a local-scale study (1:250,000), although extrapolation of the values allowed cell sizes of $1 \mathrm{~km}^{2}$. Some of these methodological issues should be addressed in future work; for instance, field gathered geographical references by use of global positioning systems (GPS) are now available for many of the villages included in this study. In spite of these difficulties, the results of the present study provided evidence for the associations of climatic and altitudinal environmental variables and the triatomines found in the endemic region for Chagas disease in Guatemala.

Further study of environmental effects on the spatial distribution and abundance of $T$. dimidiata should be prioritized. Genetic evidence and field studies suggest that $T$. dimidiata populations are panmictic and move seasonally among villages (Dorn et al., 2003) or from the natural environment into houses (Dumontiel et al., 2002; Ramirez et al. 2005). Some sylvatic populations in Guatemala have shown genetic similarities to domestic populations (Calderon et al., 2004). These observations indicate that the environments surrounding houses and villages are probably critical for the dispersal of insects, and that studies of spatial structuring should complement population genetics studies to provide a more comprehensive understanding of the dynamics of T. dimidiata.

The importance of the incorporation of the spatial component for the targeted control of triatomines is called to attention by recent studies at different spatial scales. A spatial statistics analysis conducted for a village in Argentina supported spatial clustering of T. infestans around a peridomestic structure (pig corral), which was identified as the source of reinfestation for that village (Kitron et al., 2006). In Guatemala, geographically clustered villages in Jutiapa showed persistent infestations with T. dimidiata and needed more than one spraying to substantially reduce infestation levels (Hashimoto et al., 2006). The present study indicates that, at a regional scale, two out of three Chagas disease vec- 
tors in Guatemala are geographically restricted in their distribution based on climatic factors.

Evidently, geospatial analyses could be an important component within an integrated vector management programme by facilitating a more effective planning of control activities and thus improving decision making. This should be prioritized as it appears promising for the control of Chagas vectors.

\section{Acknowledgements}

We are thankful for their hard work in collecting bugs to the personnel of the Seccion de Entomologia, Ministerio de Salud Publica y Asistencia Social de Guatemala and the personnel of the Laboratorio de Entomologia Aplicada y Parasitologia, Escuela de Biologia, Universidad de San Carlos de Guatemala. R. Monzon, Laboratorio SIG, Ministerio de Agricultura, Ganaderia y Alimentacion de Guatemala. J. P. Gaeghan, Department of Experimental Statistics, Louisiana State University. This work received financial support from the UNICEF/UNDP/World Bank/WHO Special Programme for Research and Training in Tropical Diseases (TDR), grant No.10249 awarded to M. C. Monroy.

\section{References}

Blanco E, 1943. Contribucion al estudio de los reduvideos hematofagos de Guatemala, Thesis, Universidad de San Carlos de Guatemala, Guatemala, 54 pp.

Bustamante DM, Monroy C, Menes M, Rodas A, SalazarSchettino PM, Rojas G, Pinto N, Guhl F, Dujardin JP, 2004. Metric variation among geographic populations of the Chagas vector Triatoma dimidiata (Hemiptera: Reduviidae: Triatominae) and some related species. J Med Entomol 41, 296-301.

Calderon C, Dorn PL, Melgar S, Chavez JJ, Rodas A, Rosales R, Monroy MC, 2004. A preliminary assessment of genetic differentiation of Triatoma dimidiata (Hemiptera: Reduviidae) in Guatemala by random amplification of polymorphic DNA-polymerase chain reaction. J Med Entomol 41, 882-887.
Carcavallo RU, 1999. Climatic factors related to Chagas disease transmission. Mem Inst Oswaldo Cruz 94, 367-369.

Cedillos RA, Francia H, Soundy J, Ascencio G, VolcarcelNovo M, 2001. Estudio epidemiologico del Trypanosoma cruzi en El Salvador, Universidad de El Salvador, El Salvador, $17 \mathrm{pp}$.

Curto de Casas SI, Carcavallo RU, 1984. Limites del triatomismo en la Argentina. I: Patagonia. Chagas 1, 35-40.

Dorn PL, Melgar S, Rouzier V, Gutierrez A, Combe C, Rosales R, Rodas A, Kott S, Salvia D, Monroy MC, 2003. The Chagas vector, Triatoma dimidiata (Hemiptera: Reduviidae), is panmictic within and among adjacent villages in Guatemala. J Med Entomol 40, 436-440.

Dumontiel E, Gourbiere S, 2004. Predicting Triatoma dimidiata abundance and infection rate: a risk map for Chagas disease natural transmission in the Yucatan peninsula, Mexico. Am J Trop Med Hyg 70, 514-519.

Dumonteil E, Gourbiere S, Barrera-Perez M, Rodríguez-Felix E, Ruiz H, Ruiz-Piña H, Baños-Lopez O, Ramirez-Sierra MJ, Menu F, Rabinovich JE, 2002. Geographic distribution of Triatoma dimidiata and transmission dynamics of Trypanosoma cruzi in the Yucatan peninsula of Mexico. Am J Trop Med Hyg 67, 176-183.

Elainem DA, Schorscher J, Bendall A, Obsomer V, Osman ME, Mekkawi AM, Connor SJ, Ashford RW, Thomson M, 2003. Risk mapping of visceral leishmaniasis: the role of local variation in rainfall and altitude on the presence and incidence of Kala-Azar in eastern Sudan. Am J Trop Med Hyg 68, 10-17.

Gorla DE, 2002. Variables ambientales registradas por sensores remotos como indicadores de la distribución geográfica de Triatoma infestans (Heteroptera: Reduviidae). Ecologia Austral 12, 117-127.

Hashimoto K, Cordon-Rosales C, Trampe A, Kawabata M, 2006. Impact of single and multiple residual sprayings of pyrethroid insecticides against Triatoma dimidiata (Reduviiade; Triatominae), the principal vector of Chagas disease in Jutiapa, Guatemala. Am J Trop Med Hyg 75, 226-230.

King RJ, Campbell-Lendrum DH, Davies CR, 2004. Predicting geographic variation in cutaneous leishmaniasis, Colombia. Emerg Infect Dis 10, 598-607.

Kitron U, Clennon JA, Cecere MC, Gürtler RE, King CH, Vazquez-Prokopec G, 2006. Upscale or downscale: appli- 
cations of fine scale remotely sensed data to Chagas disease in Argentina and schistosomiasis in Kenya. Geospatial Health 1, 49-58.

Landis JR, Koch GG, 1977. The measurement of observer agreement for categorical data. Biometrics 33, 159-174.

Lazzari CR, Gürtler RE, Canale D, De Mardo R, Lorenzo MG, 1998. Microclimatic properties of domestic and peridomestic Triatominae habitats in Northern Argentina. Mem Inst Oswaldo Cruz 93 (Suppl. II), 336.

Lorenzo MG, Lazzari CR, 1999. Temperature and relative humidity affect the selection of shelters by $T$. infestans, vector of Chagas disease. Acta Trop 72, 241-249.

Luz C, Fargues J, Grunewald J, 1999. Development of Rhodnius prolixus (Hemiptera: Reduviidae) under constant and cyclic conditions of temperature and humidity. Mem Inst Oswaldo Cruz 94, 403-409.

Malone JB, 2005. Biology-based mapping of vector-borne parasites by geographic information systems and remote sensing. Parassitologia 47, 27-50.

Marcilla A, Bargues MD, Ramsey JM, Magallon-Gastelum E, Salazar-Schettino PM, Abad-Franch F, Dujardin JP, Schofield CJ, Mas-Coma S, 2001. The ITS-2 of the nuclear rDNA as a molecular marker for populations, species, and phylogenetic relationships in Triatominae (Hemiptera: Reduviidae), vectors of Chagas disease. Mol Phylogenet Evol 18, 136-142.

McNally K, 2003. Developing risk assessment maps for Schistosoma haematobium based on climate grids and remotely sensed data, Thesis, Louisiana State University, USA, 42 pp.

Monroy C, Bustamante DM, Rodas A, Enriquez E, Rosales R, 2003a. Habitats, dispersion and invasion of sylvatic Triatoma dimidiata (Hemiptera: Reduviidae: Triatominae) in Peten, Guatemala. J Med Entomol 40, 800-806.

Monroy C, Bustamante DM, Rodas A, Rosales R, Mejía M, Tabaru Y, 2003b. Geographic distribution and morphometric differentiation of Triatoma nitida Usinger 1939 (Hemiptera: Reduviidae: Triatominae) in Guatemala. Mem Inst Oswaldo Cruz 98, 37-43.

Monroy C, Mejia M, Rodas A, Rosales R, Horio H, Tabaru $\mathrm{Y}, 1998$. Comparison of indoor searches with whole house demolition collections of the vectors of Chagas disease and their indoor distribution. Med Entomol Zool 49, 195-200.

Monroy C, Mejia M, Rodas A, Tabaru Y, 1996.
Intradomiciliary ecology of Triatoma dimidiata (Reduviidae: Triatomine) in Santa Maria Ixhuatan, Guatemala. XIV International Congress of Tropical Medicine and Malaria, Nagasaki, Japan, Nov 17-22.

Monroy C, Rodas A, Mejía M, Rosales R, Tabaru Y, 2003c. Epidemiology of Chagas disease in Guatemala: infection rate of Triatoma dimidiata, Triatoma nitida, and Rhodnius prolixus (Hemiptera, Reduviidae) with Trypanosoma cruzi and Trypanosoma rangeli (Kinetoplastida, Trypanosomatidae). Mem Inst Oswaldo Cruz 98, 305-310.

Nakagawa J, Cordon-Rosales C, Juarez J, Itzep C, Nonami T, 2003a. Impact of residual spraying on Rhodnius prolixus and Triatoma dimidiata in the department of Zacapa in Guatemala. Mem Inst Oswaldo Cruz 98, 277-281.

Nakagawa J, Hashimoto K, Cordon-Rosales C, Juares JA, Trampe A, Marroquin L, 2003b. The impact of vector control on Triatoma dimidiata in the Guatemalan department of Jutiapa. Ann Trop Med Parasitol 97, 289-298.

Panzera F, Ferrandis I, Ramsey J, Ordonez R, SalazarSchettino PM, Cabrera M, Monroy MC, Bargues MD, Mas-Coma S, O'connor JE, Angulo VM, Jaramillo N, Cordon-Rosales C, Gomez D, Perez R, 2006. Chromosomal variation and genome size support existence of cryptic species of Triatoma dimidiata with different epidemiological importance as Chagas disease vectors. Trop Med Int Health 11, 1092-1103.

Pifano CFR, 1969. Algunos aspectos en la ecología y epidemiología de las enfermedades endémicas con focos naturales en el area tropical, especialmente en Venezuela. Public Bibliot Arch Min San Asist Social, Caracas, 297 pp.

Ramirez CJ, Jaramillo CA, Delgado M, Pinto N, Aguilera G, Guhl F, 2005. Genetic structure of sylvatic, peridomestic and domestic populations of Triatoma dimidiata (Hemiptera: Reduviidae) from an endemic zone of Boyaca, Colombia. Acta Trop 93, 23-29.

Ramsey JM, Ordonez R, Curz-Celis A, Alvear AL, Chavez V, Lopez R, Pintor JR, Gama F, Carrillo S, 2000. Distribution of domestic Triatominae and stratification of Chagas disease transmission in Oaxaca, Mexico. Med Vet Entomol 14, 19-30.

SAS Institute, 2002. SAS/STAT User's Guide, Version 9, Cary, NC, USA.

Schofield CJ, 2000. Challenges of Chagas disease vector con- 
trol in Central America, World Health Organization, WHO/CDS/WHOPES/GCDPP/2000.1, 36 pp.

Schofield CJ, Dujardin JP, 1997. Chagas disease vector control in Central America. Parasitol Today 13, 141-144.

Stokes ME, Davis CS, Koch GG, 2000. Categorical data analysis using the SAS System, 2 ed., SAS Publishing, Cary, NC, USA, 626 pp.
Tabaru Y, Monroy M, Rodas A, Mejia M, Rosales R, 1999. The geographical distribution of vectors of Chagas disease and populations at risk of infection in Guatemala. Med Entomol Zool 50, 9-17.

WHO, 2000. Control of Chagas disease: second report of the WHO expert committee, WHO Tech Rep Ser No. 905, Brasilia, Brazil, 109 pp. 